Chantal T. Crochetière MD, Claude A. Trépanier MD FRCPC, Jacques J. Coté MD FRCPC

\title{
Epidural anaesthesia for Caesarean section: comparison of two injection techniques
}

Two techniques of injection for epidural anaesthesia for Caesarean sections were studied. Forty-five patients were randomly divided into two groups. Patients in Group I received 20 ml of lidocaine two per cent with epinephrine via the needle at a rate of $5 \mathrm{ml} \cdot 30 \mathrm{sec}^{-1}$ after a $3 \mathrm{ml}$ test dose. Patients in Group II received the same dose of the same solution in increments of $5 \mathrm{mi}$ injected through a catheter after a $3 \mathrm{ml}$ test-dose. Each increment was injected in one minute with a delay of two minutes between injections. Top-up doses were given in both groups to obtain a T4 sensory level. There was no difference between the two groups in the quality of sensory block before delivery. However, the quality was significantly better in Group II after delivery $(P=0.02)$. The incidence of hypotension was 52.2 per cent in Group I and 13.6 per cent in Group II ( $P=0.014)$. There was no significant difference in maternal and umbilical venous lidocaine concentrations. We conclude that injection in fractional doses is a safer and more efficient technique for epidural anaesthesia for Caesarean section.

After reports of fatal accidental intravenous injections of bupivacaine in obstetric anaesthesia, ${ }^{1}$ many authors recommended the use of a test dose and injection of local anaesthetic in fractionnal doses through an epidural catheter. ${ }^{2.3}$ Like others, ${ }^{4}$ we had the feeling that the quality of analgesia produced with such a technique was inferior to the one produced with a bolus injection through the needle. The present study was designed to compare

\section{Key words}

ANAESTHETIC TECHNIQUES: epidural; ANAESTHETICS LOCAL: lidocaine; ANAESTHESIA: obstetric; COMPLICATIONS: hypotension.

From the Département d'Anesthésie, Hôpital de l'EnfantJésus, Université Laval, Québec.

Presented at the Congrès Franco-Québecois d'AnesthésicRéanimation, Paris, September 1987.

Address correspondence to: Dr. Claude Trépanier, Département d'anesthésie, Hôpital de l'Enfant-Jésus, 1401, 18e rue, Québec, G1J 124. these two techniques of injection for Caesarean section with regard to the quality of analgesia, the incidence of complications and the maternal and fetal plasma concentrations of local anaesthetic.

\section{Methods}

Institutional research committee approval and informed consent were obtained. Forty-five ASA physical status I patients undergoing elective Caesarean sections were studied prospectively. We excluded patients in active labour, those with a contra-indication to an epidural block or signs of toxaemia gravidis. Each patient had requested epidural analgesia for her Caesarean section.

All patients received as pre-medication, ranitidine 150 $\mathrm{mg} P O$ the night before and one hour pre-op plus sodium citrate $0.3 \mathrm{M} 30 \mathrm{ml}$ when leaving the ward. Upon arrival in the operating room, ECG monitoring was started and blood pressure was monitored with an oscillometric automatic device (Dinamap ${ }^{\circledR}$ ). Blood pressure readings were taken twice before the beginning of the procedure, every minute for 20 minutes from the start of the epidural injection and every three minutes thereafter. All patients received a bolus of 1000 to $1500 \mathrm{ml}$ of lactated Ringer's solution through a 16-gauge IV catheter before the beginning of the anaesthetic. Epidural puncture was made by the loss of resistance technique at the L3-LA interspace with a 17-gauge Tuohy needle while the patient was in the sitting position.

Patients were randomly divided into two groups. Patients in Group I received $20 \mathrm{ml}$ of lidocaine 2 per cent with freshly added epinephrine $1 / 200,000$ via the needle at a rate of $5 \mathrm{ml} \cdot 30 \mathrm{sec}^{-1}$ after a $3 \mathrm{ml}$ test dose of the same solution. Then a 19 -gauge Portex ${ }^{\circledast}$ catheter was inserted $2-3 \mathrm{~cm}$ into the epidural space. Group II had the catheter inserted before any injection. After the epidural technique, all patients were placed in the supine position with a ten degree head-down tilt and with a "wedge" under the right hip. The patients in Group II then received a test dose of $3 \mathrm{ml}$ of the same agent. After three minutes, if there was no sign of IV injection (tachycardia) or subarachnoid injection (motor and sensory blockade) we injected $20 \mathrm{ml}$ of the same solution in fractional doses of $5 \mathrm{ml}$ injected 
in one minute, with a delay of two minutes between injections. In the two groups, 20 minutes after the start of the injection, we added lidocaine through the catheter in incremental doses to achieve a sensory level to $\mathrm{T} 4$ as evaluated by the pinprick test. All mothers received oxygen via nasal cannulae. Once satisfactory sensory blockade had been established, the surgical team was allowed to proceed.

The quality of analgesia was evaluated by the presence or absence of pain or discomfort during surgery, and by the need for systemic analgesia or general anaesthesia. ${ }^{3}$ Induction to delivery time was defined as the interval between the beginning of injection of local anaesthetic and delivery. The hypotensive criteria used were a systolic pressure less than $100 \mathrm{mmHg}$ or a decrease of 30 per cent from baseline. ${ }^{5}$ Printouts of the Dinamap were reviewed by an observer unaware of the patient's group and who decided if the hypotensive criteria had been met. We treated hypotension with further uterine displacement, a second bolus of lactated Ringer's solution and ephedrine $10 \mathrm{mg} \mathrm{IV.}$

Both at the attainment of $\mathrm{T} 4$ level of analgesia and at the time of delivery, maternal blood was obtained from an indwelling venous catheter. Umbilical venous blood was also obtained from a doubly clamped section of the umbilical cord for measurement of local anaesthetic concentration and blood gases. All samples were drawn with a glass syringe and were put in non-heparinized vacutainers immediately while carefully avoiding contact of the blood with the rubber cap. The plasma was removed from all samples after centrifugation and frozen until assayed for drug concentration using a fluorescent immunological polarization technique (TDX Abbott). All samples were analyzed at the same time to minimize technical variability. The samples for blood gas analysis were collected in an heparinized plastic syringe (Minitest Marquest ${ }^{(0)}$ ) and were analyzed immediately.

Data were analyzed for statistical significance using Student's $t$ test, the Chi square test and Fischer's exact rest when appropriate. A $P$ value $<0.05$ was considered statistically significant. Data are presented as mean \pm SD.

\section{Results}

No statistically significant differences with respect to age, weight and height were found between the two groups. Patients characteristics are presented in Table I. No serious complications occurred during the epidural techniques. We aspirated blood at the introduction of the epidural catheter in four subjects in Group I and three in Group II and reintroduced it successfully in all cases. The total dose of lidocaine administered was $27 \pm 3.4 \mathrm{ml}$ in Group 1 and $27 \pm 4.1 \mathrm{ml}$ in Group II. No patient experienced
TABLE I Demographic data

\begin{tabular}{lrc}
\hline & Group I & Group 2 \\
\hline Weight $(\mathrm{kg})$ & $70 \pm 7.2$ & $75 \pm 13.7$ \\
Height $(\mathrm{cm})$ & $158 \pm 6.7$ & $157 \pm 7.2$ \\
\hline
\end{tabular}

$P=N S$ (Student's t test).

TABLE II Efficacy of sensory block*

\begin{tabular}{|c|c|c|c|}
\hline & & $\begin{array}{l}\text { Group } 1 \\
(n=23)\end{array}$ & $\begin{array}{l}\text { Group II } \\
(n=22)\end{array}$ \\
\hline \multicolumn{2}{|c|}{ Before delivery A } & 22 & 21 \\
\hline & B & 0 & 0 \\
\hline & $\mathrm{C}$ & 0 & 1 \\
\hline & $D$ & I & 0 \\
\hline \multirow[t]{4}{*}{ After delivery } & A & 13 & 20 \\
\hline & B & 3 & 0 \\
\hline & C & 6 & 2 \\
\hline & D & 1 & 0 \\
\hline
\end{tabular}

Block significantly better in Group II after delivery $(P=0.02)$

(Fisher Exact test).

*After Dutton er al.

A. Procedure totally painless.

B. Mild discomfort requiring no supplemental analgesia.

C. Discomfort requiring supplementary analgesia.

D. Inadequate block (general anaesthesia required)

TABLE JII Lidocaine plasma concentrations

\begin{tabular}{lll}
\hline & Group I & Grotu $/ I$ \\
\hline Attainment of $\mathrm{T} 4$ level & $2.39 \pm 0.72$ & $1.99 \pm 0.74$ \\
Matemal vein $\left(\mu \mathrm{g} \cdot \mathrm{ml}^{-1}\right)$ & $2.45 \pm 0.62$ & $2.34 \pm 0.70$ \\
Delivery matemal vein $\left(\mu \mathrm{g} \cdot \mathrm{ml}^{-1}\right)$ & $1.20 \pm 0.29$ & $1.03 \pm 0.30$ \\
Delivery umbilical vein $\left(\mu \mathrm{g} \cdot \mathrm{ml}^{-1}\right)$ & &
\end{tabular}

$P=N S$ (Student's $t$ test).

symptoms of toxicity even after $36 \mathrm{ml}$ in one patient. There was no difference between the two groups in the induction to delivery times; $43 \mathrm{~min}$ in Group I and $44 \mathrm{~min}$ in Group II.

The incidence of hypotension necessitating ephedrine administration was 52.2 per cent in Group I and 13.6 per cent in Group II $(P=0.014)$. The data on the quality of analgesia are summarized in Table II. Before birth, every patient except one in each group experienced no discomfort. On the other hand, after birth, the efficacy of the sensory block was significantly better in the second group $(P=0.02)$. The condition of all neonates was satisfactory (Apgar score $=9$ or 10 at $5 \mathrm{~min}$ ) and no difference could be found between the groups. Umbilical venous acidbase status was within normal limits in all newborns. Plasma concentrations of lidocaine are presented in Table III. There was no statistically significant difference 
between the two groups either in maternal or umbilical vein samples.

\section{Discussion}

One important finding of this investigation is that we found a significant difference between the two techniques of injection with regard to the quality of analgesia. Our starting assumption that a bolus injection results in better analgesia was not confirmed but injection in fractional doses resulted in better analgesia. Several factors might explain our results. A rapid single injection causes an elevation of residual pressure in the epidural space especially in pregnant women whose epidural space compliance is reduced. Bromage demonstrated that residual epidural pressure correlates with segmental spread. ${ }^{6}$ Therefore, if a higher spread of local anaesthetic results from a bolus injection, each nerve root will be less exposed to the drug and more veins will contribute to the reabsorption process. ${ }^{6.7}$ This hypothesis seems to be confirmed by the finding that at the attainment of $\mathrm{T} 4$ block, lidocaine concentrations were higher in Group I, although this difference did not achieve statistical significance $(P=0.06)$. Also, a higher pressure in the epidural space contributes to increased leak of local anaesthetic through intervertebral foramina, which are more permeable in young adults. ${ }^{6}$ Consequently, a slower injection rate seems to result in better impregnation of nerve roots because of lesser segmental spread, decreased vein exposure and drug reabsorption as well as a smaller leak through intervertebral foramina. All three factors may contribute to the higher quality of analgesia found in Group II. These data are in agreement with Eldemir et al. who found both an increased segmental spread and a higher incidence of spotty block with a rapid injection rate. $^{8}$

The difference between the two groups was detected only after delivery. The mean induction to delivery time was 44 minutes. Therefore it is unlikely that the block was receding by that time, since we know that the time to recession of two segments for lidocaine two per cent with epinephrine is $97 \pm 19$ minutes from the onset of the block. ${ }^{6}$ On the other hand, a more intense surgical stimulation, repairing the uterus with exteriorisation and the loss of psychological support (father and newborn leaving the operating room), could have helped us to discriminate between two blocks that seemed of equal quality before birth because of a lesser stimulus.

The incidence of hypotension in Group I, 52.2 per cent, can be compared with similar studies, $\mathrm{T} 4$ level for elective Caesarean section, by Craft et al. ( 65 per cent) ${ }^{9}$ Brizgys et al. (35-43 per cent). ${ }^{10}$ Craft et al. used only $700 \mathrm{ml}$ of IV fluid to prehydrate and that could explain their higher incidence. Brizgys et al. used mostly bupivacaine ( 70 per cent of their population), a slower-acting drug. We used lidocaine with freshly added epinephrine which results in a higher $\mathrm{pH} .{ }^{11}$ It has recently been shown that alkalinized solutions produce a more rapid onset and an increased incidence of hypotension. ${ }^{12}$ The fact that a more rapid onset of block correlates with more haemodynamic changes was already known and this is the most likely explanation for the difference between Brizgy's study and ours. The striking difference between our two groups (52.2 per cent vs 13.6 per cent) can be explained by the slower onset of sympathetic blockade in Group 11 allowing more time for the compensatory mechanisms to take place. Indeed, vasoconstriction above this level of blockade is rapid but autoregulation of precapillary sphincters is a slower compensating mechanism. ${ }^{13}$ The slower onset of sympathetic blockade in Group II probably allowed more time for the latter mechanism to be effective. The incidence of hypotension reported in the literature varies according to the volume of prehydratation,,$^{14}$ to the extent of epidural block and the presence or absence of labour. ${ }^{14}$ Our data suggest that the speed of injection can be an important factor in the occurrence of this complication.

We did not find any significant difference between the two groups in the maternal venous plasma lidocaine concentrations. The highest measured level $4.4 \mu \mathrm{g}^{\prime} \mathrm{ml}^{-1}$, was well below the convulsive threshold, $10-12 \mu \mathrm{g} \cdot \mathrm{ml}^{-1},{ }^{15}$ and no patient experienced any symptoms of toxicity. However, we collected only two specimens and could have missed a peak. Peak plasma levels occur between 20 and $\mathbf{3 0}$ minutes in lumbar epidural block using lidocaine with epinephrine: concentrations decrease very slowly after that. ${ }^{16,17}$ Our samples were taken $25.5 \pm 8.04$ and $43.4 \pm 7.65$ minutes after the beginning of injection in Group I and 26.2 \pm 8.0 and $43.6 \pm 8.08$ minutes in Group II. The chances that a major peak was missed are low but we cannot rule out that the top-up doses given to reach T4 resulted in a delayed elevation of the plasma concentration that was not detected by our sampling technique. Finally the umbilical venous levels were all under 2.5 $\mu \mathrm{g} \cdot \mathrm{ml}^{-1}$, which is the level reported by Shnider $e t$ al. to be safe for the newborn. ${ }^{18}$

In conclusion, we found that epidural anaesthesia for Caesarean section with injection of local anaesthesic in fractional doses results in more profound analgesia and a lower incidence of hypotension than bolus injection. These advantages combined with the decreased potential of systemic toxicity from inadvertent massive vascular injection suggest that the use of fractional doses is a safer and more efficient technique for epidural anaesthesia for Caesarean section than single bolus injection. 


\section{Acknowledgements}

The authors thank Mrs. Suzanne Koënig for typing the manuscript, Dr. Michel Rouillard and Dr. Pierre Denaul for their cooperation and Dr. Jacques Brisson for his help with statistical analysis.

\section{References}

IFDA. Drug Bulletin. 1983. Adverse reactions with Bupivacaine. US Dept of Health and Human Services publication, no 13(3): 23. Rockville, Md.

2 Moir DD. Local anaesthetic techniques in obstetrics. Br $\mathrm{J}$ Anaesth 1986; 58: 747-59.

3 Duton DA, Moir DD, Howie HB, Thorburn J, Watson

$R$. Choice of local anaesthetic drug for extradural caesarean section. Br J Anaesth 1984; 56: 1361-8

4 Metha $P$. Theriot E. Mehrotra et al. Technique of injection, maternal position and spread of ancsthetic in cpidural anesthesia. Ancsthesiology 1983; 59: A410.

5 Shnider $5 M$, Levinson $G$. Anesthesia for caesarean section. In: Anesthesia for obstetrics. 2nd ed. Baltimore: Williams and Wilkins 1987: 159-78.

6 Bromage $P R$, Epidural Analgesia. Philadelphia, W.B Saunders, 1978; 129: 174-239.

7 Cohen S, Luykx NM, Marx GF. High versus low flow rates during lumbar epidural block. Reg Anesth 1984; 9 : 8-11.

8 Eldemir HA, Soper LE, Sweet RB. Studies of factors affecting peridural anesthesia. Anesth Analg 1965; 44: $400-4$.

9 Craft JB, Roizen, MF, Dao SD, Edward M, Gilman $R$ A comparison of $\mathrm{T} 4$ and $\mathrm{T} 7$ dermatomal levels of analgesia for Caesarean section using the lumbar epidural technique. Can Anaesth Soc J 1982; 29: 264-9.

10 Brizgys RV, Dailey PA, Shnider SM, Kotelko DM, Levinson $G$. The incidence and neonatal effects of maternal hypotension during epidural anesthesia for cesarean section. Anesthesiology 1987; 67: 782-6

11 Difazio CA, Carron H, Grosslight KR, Moscicki JC, Bolding WR. Johns RA. Comparison of $\mathrm{pH}$-adjusted lidocaine solutions for epidural anesthesia. Anesth Analg 1986; 65: 760-4.

12 Parnass SM, Curran MJA, Becker GL. Incidence of hypotension associated with epidural anesthesia using alkalinized and nonalkalinized lidocaine for cesarean section. Anesth Aralg 1987; 66: 1148-50.

13 Cousins MJ, Bridenbaugh PO. Neural blockade. Philadelphia: J.B. Lippincott, 1980; 203.

14 Lewis $M$, Thomas $P K$, Wilkes $R G$. Hypotension during epidural analgesia for caesarean section: Arterial and cencral venous pressure changes after acute intravenous loading with two litres of Hartmann's solution. Anaesthesia $1983 ; 38: 250-3$.
15 Albright A, Ferguson II JE, Joyce III TH, Stevenson DK. Anesthesia in obstetrics. 2nd ed. Boston: Butterworths, 1986: 124.

16 Braid DP, Scot $D B$. The systemic absorption of local analgesic drugs. Br J Anaesth 1965; 37: 394-404.

17 Mazze RI, Dunbar RW. Plasma lidocaine concentrations after caudal, lumbar, epidural, axillary block and intravenous regional anesthesia. Anesthesiology 1966;27: 574-9.

18 Shnider SM, Way EL. Plasma levels of lidocaine in mother and newbom following obstetrical conduction anesthesia: clinical applications. Anesthesiology 1968; 29: 951 .

\section{Résumé}

Les auteurs ont étudié deux techniques d'injection pour anesthésie épidurale lors de césariennes. Quarante-cinq patientes ont été divisées de façon aléatoire en dewx groupes. Les patientes du groupe I ont regu $20 \mathrm{ml}$ de lidocaine deux pour cent avec épinéphrine par l'aiguille dà une vitesse d'injection de 5 $\mathrm{ml} \cdot 30 \mathrm{sec}^{-1}$ après une dose-test de $3 \mathrm{ml}$. Les patientes du groupe II ont rȩ̧u la même dose du même agent via un cathéter épidural, par doses fracionnées de $5 \mathrm{ml}$ après la dose-test. Les doses fractionnées furent injectées en une minute, d intervalle de deux minutes entre chacune des injections. Des doses supplémentaires furent ajoutées dans les deux groupes pour obtenir un niveau sensitif à $T 4$. Il $n$ ' y a eu aucune différence entre les deix groupes quant à la qualité du bloc sensitif avant la naissance. Cependant, après la naissance. le bloc fut significativement meilleur dans le groupe $I(P=0.021)$. L'incidence d'hypotension fut de 52.2 pour cent dans le groupe 1 et de 13.6 pour cent dans le groupe $\|(P=0.014)$. Il $n^{\prime} y$ a pas cu de différence significative entre les niveaw plasmatiques de lidocaine dans les veines matermelles et ombilicales. Nous concluons que l'injection en doses fractionnées est une technique à la fois plus sécuritaire et plus efficace pour l'anesthésie épidurale lors d'une césarienne. 